International Journal of Engineering \& Technology, $7(3.2)(2018) 419-424$
International Journal of Engineering \& Technology
SPC
Website: www.sciencepubco.com/index.php/IJET
Research paper

\title{
Theoretical Studies of Stresses in a Layer of a Light-Concrete Mixture, Which is Compacted on the Shock-Vibration Machine
}

\author{
Mykola Nesterenko $^{1} *$ Tetyana Nesterenko $^{2}$, Taras Skliarenko ${ }^{3}$ \\ ${ }^{1}$ Poltava National Technical Yuri Kondratyuk University, Ukraine \\ ${ }^{2}$ Poltava National Technical Yuri Kondratyuk University, Ukraine \\ ${ }^{3}$ Poltava National Technical Yuri Kondratyuk University, Ukraine \\ *Corresponding Author E-Mail: Nesterenkonikola@Gmail.Com
}

\begin{abstract}
The article presents the design of shock-and-vibration machine for the formation of lightweight concrete products. The results of theoretical studies of the working process of the shock-and-vibration machine with the definition of motion and stress laws in a layer of a concrete mixture compacted in the kinematic excitation of oscillations are given.

In paper the dependences for determining the reduced mass and the equivalent coefficient of inelastic resistance of a concrete mixture with asymmetric kinematic excitation of oscillations during the vibration seal are given. The practical application of the obtained results is offered.
\end{abstract}

Keywords: shock-and-vibration machine, light concrete mix, compaction of the concrete mixture, stress in the layer of concrete mix.

\section{Introduction}

The practice of recent years shows that one of the most promising construction methods, which provide high rates of building construction, is frame-block and block construction. During construction, there is a need for a large number of lightweight concrete blocks, which are used as enclosing structures and have high thermal insulation and soundproofing indicators.

The formation of these products is carried out on equipment, which in most cases is made by the forces and funds of the enterprises themselves or local construction organizations.

Products that have been molded with existing equipment do not always meet the requirements for a number of indicators (strength, crack resistance and frost resistance).

Vibrating machines with a shock-and-vibrational effect are quite effective for concrete mix compaction. They are effective in forming a number of lightweight concrete products and have a number of advantages, which are, first of all, the possibility of effective formation of products from hard concrete mixtures with immediate removal of formwork, which contributes to production productivity increase, reduces the metal texture of equipment by reducing the circulation of forms and reduces energy consumption with heat treatment.

The solution of the problem can be achieved by creating vibration machines with scientifically based technological indicators [1,2]. These indicators can be determined by conducting theoretical studies of the work process of the shock-and-vibration machine.

\section{Main Body}

The bases of the theory of oscillations, taking into account the elastic and dissipative properties of the investigated medium, are given in the papers [1, 3-5], are the theoretical foundations for the methods of calculating vibration machines [1, 6-8]. In determining the calculation scheme of the vibration machine, the influence of the medium, as it follows from the analysis, is carried out according to the method of determining the influence of the adjoint mass $[9,10]$ or the distributed parameters [1]. It is assumed [1] that the most correct is the inclusion of the processed medium in the form of distributed parameters.

However, such an approach is possible for harmonic oscillations, and for shock and shock-and-vibration oscillations, such an approach is difficult to apply, due to the fact that under such modes there are different from the basic other frequencies, and then the principle of superposition is not possible. Therefore, a mixed discrete-continuum model is adopted in the work, which is constructed for the following reasons. It is assumed that the processed medium is modeled by a system with distributed parameters, and in the general equation of motion in the system "machine-product" is included in the discrete form. This approach allows us to draw up a general calculation scheme, and the equations of motion are based on consideration of the contact area acceleration.

The stresses in the layer of light concrete mix will arise as a result of compaction on the shock-and-vibration machine. Figure 1 depicts a structural scheme of the machine [10-12]. It consists of a frame 1 which is a rigid box-shaped design and consists of a welded frame made of profile metal, sewn with metal sheets. In the lower part of the movable frame and the upper part of the base 
there are elastic pads 2 . The movable frame is fixed relating to the base with the help of inclined mounted springs 3 , and also interacts with elastic elements 4 whose rigidity can be adjusted. The device is operated by means of a cam mechanism 5 which rotates with the help of an electric motor.

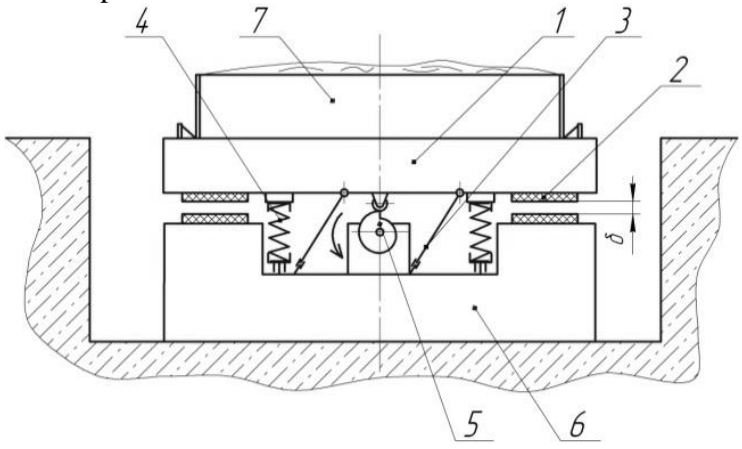

Fig. 1: Construction of shock-and-vibration machine for concrete mixes products compaction

The device works as follows. After loading the concrete mixture into the form 6 , the electric motor is activated and the lifting of the movable frame 1 is carried out by means of the cam mechanism to the height, in the further rotation of the cam there is a fall of the moving frame on the elastic liners 2 , placed on a stationary frame 6. During the impact, there is a vibration that affects the compacted mixture. Depending on the stiffness of the mixture loaded to the form, it is possible to adjust the stiffness of the elastic elements 4. It is known [1], the medium provides resistance to movement of the operating device its inertia and elastic-dissipative components that similarly called reactive (elastic-inertial) and active (dissipative) components. [13] In accordance with the accepted method [1], the influence of the medium is considered by the classical solution of the equation of motion, taking into account the boundary conditions (forces acting on the operating device in the contact zone or, for example, the amplitudes of the oscillations of the operating device and the medium in contact are the same, and on the surface - pressure is zero). In this case we obtain the general formula for determining the law of the compacted medium in the vertical direction.

The movement of the compacted medium in the direction of the coordinate (Fig. 2) can be described by the wave equation in partial derivatives:

$E^{*} \frac{\partial^{2} u(z, t)}{\partial z^{2}}=\rho \frac{\partial^{2} u(z, t)}{\partial t^{2}}$,

where $u, z$-Eulerian and Lagrangian coordinates;

$\rho$ - density of concrete mix;

$E^{*}$ - complex deformation module of a concrete mix,

$E^{*}=E(1+i \gamma)$

$E$ - modulus of elastic deformation of concrete mix;

$\gamma-$ the resistance coefficient, which determines the part of the energy of the medium absorbed during one period of oscillation;

$i$ - standard unit indicating shear elastic component of the vector to non-elastic (dissipative) . Substituting expression (2) into identical equation (1), we obtain the equation of compacted medium motion in the following form:

$\frac{\partial^{2} u(z, t)}{\partial z^{2}}-\frac{\rho}{E(1+i \gamma)} \frac{\partial^{2} u}{\partial t^{2}}=0$.

To solve the wave equation of oscillations, we use the following boundary conditions: $u(0, t)=z(t)=\frac{A}{2} e^{2 i n \pi}+\sum_{n=1}^{n} A_{n} e^{i n \omega t}$

$E S \frac{\partial u(h, t)}{\partial z}=0$

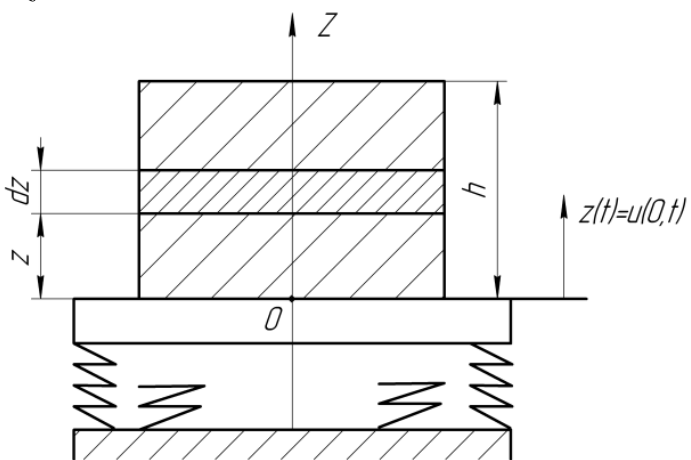

Fig. 2: The calculation scheme of the dynamic system "vibroplate - compacted medium"

The solution of the wave equation of oscillation is represented as an imaginary part of the complex function:

$u(z, t)=\sum_{n=1}^{n} u_{n}(z, t)=\sum_{n=1}^{n} U_{n}(z) e^{i n \omega t}$,

where $u_{n}(z, t)$ - the solution of the wave equation of oscillation (2) for one of the harmonics of the forced oscillations $n \omega$,

$u_{n}(z, t)=U_{n}(z) e^{i n \omega t}$

$U_{n}(z)$ - the complex amplitude of oscillations on one of the harmonics of forced oscillations $n \omega$.

Substituting solution (6) into equation (3), we obtain the following differential equation for determining complex oscillations in one of the harmonics $n \omega$ :

$\frac{\partial^{2} U_{n}(z)}{\partial z^{2}}-\frac{\rho n^{2} \omega^{2}}{E(1+i \gamma)} U_{n}(z)=0$

Convert the equation (8) to the following form:

$\frac{\partial^{2} U_{n}(z)}{\partial z^{2}}-k_{n}^{2} U_{n}(z)=0$

where $k_{n}$ - complex wave number,

$k_{n}=\sqrt{\frac{\rho n^{2} \omega^{2}}{E(1+i \gamma)}}$.

The solution of the resulting equation of oscillation (9) will have the following form:

$U_{n}(z)=U_{1 n} e^{k_{n} z}+U_{2 n} e^{-k_{n} z}$

where $U_{1 n}, U_{2 n}$ - continuous integration, complex amplitudes, which are determined from the boundary conditions (4) and (6). Substituting expression (11) in identical equation (7) we find the solution of the equation of oscillation for one of the harmonics in the following form:

$u_{n}(z, t)=\left(U_{1 n} e^{k_{n} z}+U_{2 n} e^{-k_{n} z}\right) e^{i n \omega t}$.

The complex wave number can be represented as follows: 


$$
k_{n}=\left(a_{n}+i \beta_{n}\right),
$$

where $a_{n}$ - energy absorption coefficient characterizing the process of damping the oscillations;

$$
\beta_{n}-\text { wave number. }
$$

Substituting expression (13) into identical equation (10) and equating an individually imaginary and valid part, we find the value of the coefficients in the following form:

$$
\alpha_{n}=\frac{n \omega}{c_{x b}} \sqrt{\frac{\sqrt{1+\gamma^{2}}+1}{2\left(1+\gamma^{2}\right)}}
$$

$$
\beta_{n}=\frac{n \omega}{c_{x b}} \sqrt{\frac{\sqrt{1+\gamma^{2}}-1}{2\left(1+\gamma^{2}\right)}},
$$

where $c_{x b}$ - the phase velocity of propagation of vibrations in a compacted medium, $c_{x s}=\sqrt{E / \rho}$.

With consideration of the expression (13), the solution (12) turns to the following form:

$$
u_{n}(z, t)=\left[U_{1 n} e^{\left(a_{n}+i \beta_{n}\right) z}+U_{2 n} e^{-\left(a_{n}+i \beta_{n}\right) z}\right] e^{i n \omega t} .
$$

To determine the permanent integration we substitute the expression (16) into the boundary condition (5), find the relation between constant integration $U_{1 n}$ and $U_{2 n}$ :

$$
U_{1 n}=U_{2 n} \frac{e^{-\left(\alpha_{n}+i \beta_{n}\right) h}}{e^{\left(\alpha_{n}+i \beta_{n}\right) h}} .
$$

Substituting the formula (17) to expression (16), we find the solution of the equation of oscillation for one of the frequencies of the forced oscillations in the following form:

$$
u_{n}(z, t)=\left[U_{2 n} \frac{e^{-\left(a_{n}+i \beta_{n}\right)(h-z)}+e^{\left(a_{n}+i \beta_{n}\right)(h-z)}}{e^{\left(a_{n}+i \beta_{n}\right) h}}\right] e^{i n \omega t} .
$$

Continuous integration we find as a result of substituting expression (18) into a modified boundary condition (4) only using one forced harmonic oscillations, ie:

$$
u_{n}(0, t)=\left[U_{2 n} \frac{e^{-\left(a_{n}+i \beta_{n}\right) h}+e^{\left(a_{n}+i \beta_{n}\right) h}}{e^{\left(a_{n}+i \beta_{n}\right) h}}\right] e^{i n \omega t}=\frac{A}{2} e^{2 i n \pi}+A_{n} e^{i n \omega t} .
$$

Designating the following

$$
U_{2 n}=U_{3 n}+\frac{A}{2} e^{2 i n \pi} \frac{e^{\left(a_{n}+i \beta_{n}\right) h} e^{-i n \omega t}}{e^{-\left(a_{n}+i \beta_{n}\right) h}+e^{\left(a_{n}+i \beta_{n}\right) h}}
$$

and, substituting it in the expression (19), we will find

$$
U_{3 n}=A_{n} \frac{e^{\left(a_{n}+i \beta_{n}\right) h}}{e^{-\left(a_{n}+i \beta_{n}\right) h}+e^{\left(a_{n}+i \beta_{n}\right) h}} .
$$

Using expressions (20) and (21) we find constant integration in the following form:

$$
U_{2 n}=A_{n} \frac{e^{\left(a_{n}+i \beta_{n}\right) h}}{e^{-\left(a_{n}+i \beta_{n}\right) h}+e^{\left(a_{n}+i \beta_{n}\right) h}}+\frac{A}{2} e^{2 i n \pi} \frac{e^{\left(a_{n}+i \beta_{n}\right) h} e^{-i n \omega t}}{e^{-\left(a_{n}+i \beta_{n}\right) h}+e^{\left(a_{n}+i \beta_{n}\right) h}} .
$$

Substituting the found constant integration into the expression (18), we find the solution of the oscillation wave equation of (3) for one single oscillation frequency:

$$
\begin{aligned}
& u_{n}(z, t)=\left[A_{n} \frac{e^{-\left(a_{n}+i \beta_{n}\right)(h-z)}+e^{\left(a_{n}+i \beta_{n}\right)(h-z)}}{e^{-\left(a_{n}+i \beta_{n}\right) h}+e^{\left(a_{n}+i \beta_{n}\right) h}}\right] e^{i n \omega t}+ \\
& +\frac{A}{2} e^{2 i n \pi} \cdot \frac{e^{-\left(a_{n}+i \beta_{n}\right)(h-z)}+e^{\left(a_{n}+i \beta_{n}\right)(h-z)}}{e^{-\left(a_{n}+i \beta_{n}\right) h}+e^{\left(a_{n}+i \beta_{n}\right) h}} .
\end{aligned}
$$

After simple transformations, we represent the correspondence (23) in the following form:

$$
\begin{aligned}
& u_{n}(z, t)= \\
& =A_{n} \frac{\operatorname{ch}\left[\alpha_{n}(h-z)\right] \cos \left[\beta_{n}(h-z)\right]+i \operatorname{sh}\left[\alpha_{n}(h-z)\right] \sin \left[\beta_{n}(h-z)\right]}{\operatorname{ch}\left(\alpha_{n} h\right) \cos \left(\beta_{n} h\right)+i \operatorname{sh}\left(\alpha_{n} h\right) \sin \left(\beta_{n} h\right)} \times \\
& \times(\cos n \omega t+i \sin n \omega t)+ \\
& +\frac{A}{2} \cdot \frac{\operatorname{ch}\left[\alpha_{n}(h-z)\right] \cos \left[\beta_{n}(h-z)\right]+i \operatorname{sh}\left[\alpha_{n}(h-z)\right] \sin \left[\beta_{n}(h-z)\right]}{\operatorname{ch}\left(\alpha_{n} h\right) \cos \left(\beta_{n} h\right)+i \operatorname{sh}\left(\alpha_{n} h\right) \sin \left(\beta_{n} h\right)} \times \\
& \times(\cos 2 \pi n+i \sin 2 \pi n) .
\end{aligned}
$$

Multiplying the numerators and denominators of the terms of the expression (24) to the complex function conjugate to the denominator, and separating the imaginary part from the first clause, and from the second clause the real part, and using expression (6), we obtain the desired solution of equation (3), which satisfies the boundary conditions (4) and (5):

$$
\begin{aligned}
& u(z, t)=\sum_{n=1}^{n} A_{n}\left\{\frac{\operatorname{ch}\left[\alpha_{n}(h-z)\right] \cos \left[\beta_{n}(h-z)\right] \operatorname{ch}\left(\alpha_{n} h\right) \cos \left(\beta_{n} h\right)}{\operatorname{sh}^{2}\left(\alpha_{n} h\right)+\cos ^{2}\left(\beta_{n} h\right)}+\right. \\
& \left.+\frac{s h\left[\alpha_{n}(h-z)\right] \sin \left[\beta_{n}(h-z)\right] \operatorname{sh}\left(\alpha_{n} h\right) \sin \left(\beta_{n} h\right)}{\operatorname{sh}^{2}\left(\alpha_{n} h\right)+\cos ^{2}\left(\beta_{n} h\right)}\right\} \sin n \omega t+ \\
& +\frac{A}{2}\left\{\frac{c h\left[\alpha_{1}(h-z)\right] \cos \left[\beta_{1}(h-z)\right] \operatorname{ch}\left(\alpha_{1} h\right) \cos \left(\beta_{1} h\right)}{\operatorname{sh}^{2}\left(\alpha_{1} h\right)+\cos ^{2}\left(\beta_{1} h\right)}+\right. \\
& \left.+\frac{s h\left[\alpha_{1}(h-z)\right] \sin \left[\beta_{1}(h-z)\right] \operatorname{sh}\left(\alpha_{1} h\right) \sin \left(\beta_{1} h\right)}{\operatorname{sh}^{2}\left(\alpha_{1} h\right)+\cos ^{2}\left(\beta_{1} h\right)}\right\}
\end{aligned}
$$

where $\alpha_{1}$ and $\beta_{1}$ - the energy absorption coefficient and the wave number are determined from expressions (14) and (15) at the basic angular frequency of oscillations $\omega$, generated by the cam mechanism. The stresses occurring in the layer of a compacted concrete mixture are determined from the following expression:

$$
\begin{aligned}
& \sigma(z, t)=E \frac{\partial u(z, t)}{\partial z}=-\sum_{n=1}^{n} E \cdot A_{n} \times\left\{\frac{\sqrt{\left(\alpha_{n}^{2}+\beta_{n}^{2}\right) \operatorname{sh}^{2} \alpha_{n} h+\alpha_{n}^{2}}}{\operatorname{sh}^{2}\left(\alpha_{n} h\right)+\cos ^{2}\left(\beta_{n} h\right)} \times\right. \\
& \times \frac{\operatorname{sh}\left[\alpha_{n}(h-z)\right] \cdot \cos \left[\beta_{n}(h-z)\right] \cdot \cos \left(\beta_{n} h-\zeta_{1 n}\right)}{\operatorname{sh}^{2}\left(\alpha_{n} h\right)+\cos ^{2}\left(\beta_{n} h\right)}+ \\
& +\frac{\sqrt{\left(\alpha_{n}^{2}+\beta_{n}^{2}\right) \operatorname{sh}^{2} \alpha_{n} h+\beta_{n}^{2}} \cdot \operatorname{ch}\left[\alpha_{n}(h-z)\right] \cdot \sin \left[\beta_{n}(h-z)\right]}{s^{2}\left(\alpha_{n} h\right)+\cos ^{2}\left(\beta_{n} h\right)} \times \\
& \left.\times \frac{\sin \left(\beta_{n} h-\zeta_{2 n}\right)}{\operatorname{sh}^{2}\left(\alpha_{n} h\right)+\cos ^{2}\left(\beta_{n} h\right)}\right\} \sin n \omega t-\frac{A E}{2} \cdot\left\{\frac{\sqrt{\left(\alpha_{1}^{2}+\beta_{1}^{2}\right) \operatorname{sh}^{2} \alpha_{1} h+\alpha_{1}^{2}}}{\operatorname{sh}^{2}\left(\alpha_{1} h\right)+\cos ^{2}\left(\beta_{1} h\right)} \times\right. \\
& \times \frac{\operatorname{sh}_{[}\left[\alpha_{1}(h-z)\right] \cos \left[\beta_{1}(h-z)\right] \cos \left(\beta_{1} h-\zeta_{1}\right)}{\operatorname{sh}^{2}\left(\alpha_{1} h\right)+\cos ^{2}\left(\beta_{1} h\right)}+
\end{aligned}
$$




$$
\begin{aligned}
& +\}+\frac{\sqrt{\left(\alpha_{1}^{2}+\beta_{1}^{2}\right) \operatorname{sh}^{2} \alpha_{1} h+\beta_{1}^{2}} \cdot \operatorname{ch}\left[\alpha_{1}(h-z)\right] \cdot \sin \left[\beta_{1}(h-z)\right]}{\operatorname{sh}^{2}\left(\alpha_{1} h\right)+\cos ^{2}\left(\beta_{1} h\right)} \times \\
& \left.\times \frac{\sin \left(\beta_{1} h-\zeta_{2}\right)}{\operatorname{sh}^{2}\left(\alpha_{1} h\right)+\cos ^{2}\left(\beta_{1} h\right)}\right\}
\end{aligned}
$$

where $\zeta_{1 n}, \zeta_{2 n}, \zeta_{1}$ и $\zeta_{2}$-angles of phase shift,

$$
\begin{aligned}
& \zeta_{1 n}=\operatorname{arctg}\left[\frac{\beta_{n}}{\alpha_{n}} \operatorname{th}\left(\alpha_{n} h\right)\right] ; \\
& \zeta_{2 n}=\operatorname{arctg}\left[\frac{\beta_{n}}{\alpha_{n}} \operatorname{cth}\left(\alpha_{n} h\right)\right] ; \\
& \zeta_{1}=\operatorname{arctg}\left[\frac{\beta_{1}}{\alpha_{1}} \operatorname{th}\left(\alpha_{1} h\right)\right] ; \\
& \zeta_{2}=\operatorname{arctg}\left[\frac{\beta_{1}}{\alpha_{1}} \operatorname{cth}\left(\alpha_{1} h\right)\right] .
\end{aligned}
$$

Stresses that occur at the base layer of compacted concrete mixture, can be determined from the following expression:

$$
\begin{aligned}
& \sigma(0, t)=E \frac{\partial u(0, t)}{\partial z}=-\sum_{n=1}^{n} E \cdot A_{n}\left\{\frac{\alpha_{n} s h\left(2 \alpha_{n} h\right)-\beta_{n} \sin \left(2 \beta_{n} h\right)}{2\left[\operatorname{sh}^{2}\left(\alpha_{n} h\right)+\cos ^{2}\left(\beta_{n} h\right)\right]}\right\} e^{i n \omega t}- \\
& -\frac{A E}{2}\left\{\frac{\alpha_{1} \operatorname{sh}\left(2 \alpha_{1} h\right)-\beta_{1} \sin \left(2 \beta_{1} h\right)}{2\left[\operatorname{sh}^{2}\left(\alpha_{1} h\right)+\cos ^{2}\left(\beta_{1} h\right)\right]}\right\}
\end{aligned}
$$

or from the following one

$$
\begin{aligned}
& \sigma(0, t)=E \frac{\partial u(0, t)}{\partial z}=-\sum_{n=1}^{n} E \cdot A_{n}\left\{\frac{\alpha_{n} \operatorname{sh}\left(2 \alpha_{n} h\right)-\beta_{n} \sin \left(2 \beta_{n} h\right)}{2\left[\operatorname{sh}^{2}\left(\alpha_{n} h\right)+\cos ^{2}\left(\beta_{n} h\right)\right]}\right\} e^{i n \omega t}- \\
& -\frac{A E}{2}\left\{\frac{\alpha_{1} \operatorname{sh}\left(2 \alpha_{1} h\right)-\beta_{1} \sin \left(2 \beta_{1} h\right)}{2\left[\operatorname{sh}^{2}\left(\alpha_{1} h\right)+\cos ^{2}\left(\beta_{1} h\right)\right]}\right\}
\end{aligned}
$$

in which the harmonic components are represented as an imaginary part of the complex function.

The stresses that occur at the base of the layer of a compacted concrete mixture are substantially affected by the mass of the medium.

It is known [1], the medium provides resistance to movement of the operating device its inertia and elastic-dissipative components that similarly called reactive (elastic-inertial) and active (dissipative) components. From the equality of inertial forces and resistance forces (Fig. 3) in the contact area of the concrete mixture with the bottom of the form, and using expression (2), we obtain the following relation:

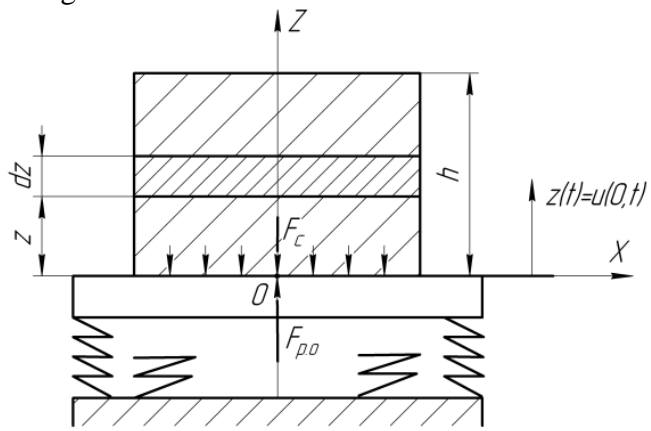

Fig. 3: Scheme to determine the reactive resistance of the medium $m_{c} \frac{d^{2} z(t)}{d t^{2}}=\frac{E S}{(1+i \gamma)} \frac{\partial u(0, t)}{\partial z}$

where $m_{c}$-attached mass of medium (concrete mix);

$S$ - the base area of the bottom of the form.

From the expression (33) follows:

$m_{c}=\frac{\frac{E S}{(1+i \gamma)} \frac{\partial u(0, t)}{\partial z}}{\frac{d^{2} z(t)}{d t^{2}}}$.

Substituting formula (32) into expression (34) and accelerating the oscillations of the movable frame $\frac{d^{2} z(t)}{d t^{2}}=-\sum_{n=1}^{n} n^{2} \omega^{2} A_{n} e^{i n \omega t}$, we obtain a functional dependence for determining the reduced mass of the concrete mixture:

$$
\begin{aligned}
& m_{c}=\frac{\sum_{n=1}^{n} \frac{E S A_{n}}{1+i \gamma}\left\{\frac{\alpha_{n} \operatorname{sh}\left(2 \alpha_{n} h\right)-\beta_{n} \sin \left(2 \beta_{n} h\right)}{2\left[\operatorname{sh}^{2}\left(\alpha_{n} h\right)+\cos ^{2}\left(\beta_{n} h\right)\right]}\right\} e^{i n \omega t}}{\sum_{n=1}^{n} n^{2} \omega^{2} A_{n} e^{i n \omega t}}+ \\
& +\frac{\frac{E S A}{2(1+i \gamma)}\left\{\frac{\alpha_{1} \operatorname{sh}\left(2 \alpha_{1} h\right)-\beta_{1} \sin \left(2 \beta_{1} h\right)}{2\left[\operatorname{sh}^{2}\left(\alpha_{1} h\right)+\cos ^{2}\left(\beta_{1} h\right)\right]}\right\}}{\sum_{n=1}^{n} n^{2} \omega^{2} A_{n} e^{i n \omega t}} .
\end{aligned}
$$

Since the amplitudes of higher harmonics of oscillations are less than the amplitude of the primary (first) harmonic of oscillations, in the first approximation the given mass of the concrete mixture can be determined from the values of the fundamental frequency of forced oscillations. At the same time expression (35) turns to the following form:

$m_{c}=\frac{E S}{(1+i \gamma) \omega^{2}}\left\{\frac{\alpha_{1} \operatorname{sh}\left(2 \alpha_{1} h\right)-\beta_{1} \sin \left(2 \beta_{1} h\right)}{2\left[\operatorname{sh}^{2}\left(\alpha_{1} h\right)+\cos ^{2}\left(\beta_{1} h\right)\right]}\right\}+$
$+\frac{A E S}{2 A_{1}(1+i \gamma) \omega^{2}}\left\{\frac{\alpha_{1} \operatorname{sh}\left(2 \alpha_{1} h\right)-\beta_{1} \sin \left(2 \beta_{1} h\right)}{2\left[\operatorname{sh}^{2}\left(\alpha_{1} h\right)+\cos ^{2}\left(\beta_{1} h\right)\right]}\right\} e^{-i \omega t}$.

Multiply the numerator and denominator of the first and second terms of expression (36) into an imaginary number conjugated to the denominator:

$$
\begin{gathered}
m_{c}=\frac{E S(1-i \gamma)}{\left(1+\gamma^{2}\right) \omega^{2}}\left\{\frac{\alpha_{1} \operatorname{sh}\left(2 \alpha_{1} h\right)-\beta_{1} \sin \left(2 \beta_{1} h\right)}{2\left[\operatorname{sh}^{2}\left(\alpha_{1} h\right)+\cos ^{2}\left(\beta_{1} h\right)\right]}\right\}+ \\
+\frac{A E S(1+i \gamma)}{2 A_{1}\left(1+\gamma^{2}\right) \omega^{2}}\left\{\frac{\alpha_{1} \operatorname{sh}\left(2 \alpha_{1} h\right)-\beta_{1} \sin \left(2 \beta_{1} h\right)}{2\left[\operatorname{sh}^{2}\left(\alpha_{1} h\right)+\cos ^{2}\left(\beta_{1} h\right)\right]}\right\}(\cos \omega t-i \sin \omega t)
\end{gathered}
$$

Separating from the complex function (37) the real part, we find the desired value of the reduced mass of the concrete mixture with asymmetric kinematic excitation of the oscillations:

$$
\begin{aligned}
& m_{c}=\frac{E S}{\left(1+\gamma^{2}\right) \omega^{2}}\left\{\frac{\alpha_{1} \operatorname{sh}\left(2 \alpha_{1} h\right)-\beta_{1} \sin \left(2 \beta_{1} h\right)}{2\left[\operatorname{sh}^{2}\left(\alpha_{1} h\right)+\cos ^{2}\left(\beta_{1} h\right)\right]}\right\} \times \\
& \times\left[1+\frac{A}{2 A_{1}}(\cos \omega t+\gamma \sin \omega t)\right] d t .
\end{aligned}
$$

The analysis of the obtained expression (38) shows that the given mass of the concrete mixture with an asymmetric kinematic excitation of oscillations is variable, ie, varies over time. 
When using a discrete model it is expedient to use a constant magnitude of the reduced mass in the form of its average value. The magnitude of the average value of the reduced mass of the concrete mix for the full cycle of a single oscillation, that is, in a time $T=t_{1}+t_{2}$ will be equal to:

$$
\begin{aligned}
& m_{c p}=\int_{0}^{t_{1}+t_{2}} \frac{E S}{\left(t_{1}+t_{2}\right)\left(1+\gamma^{2}\right) \omega^{2}}\left\{\frac{\alpha_{1} \operatorname{sh}\left(2 \alpha_{1} h\right)-\beta_{1} \sin \left(2 \beta_{1} h\right)}{2\left[\operatorname{sh}^{2}\left(\alpha_{1} h\right)+\cos ^{2}\left(\beta_{1} h\right)\right]}\right\} \times \\
& \times\left[1+\frac{A}{2 A_{1}}(\cos \omega t+\gamma \sin \omega t)\right] d t=m_{c}^{\prime}+m_{c}^{\prime \prime}= \\
& =\int_{0}^{t_{1}} \frac{E S}{\left(t_{1}+t_{2}\right)\left(1+\gamma^{2}\right) \omega^{2}}\left\{\frac{\alpha_{1} \operatorname{sh}\left(2 \alpha_{1} h\right)-\beta_{1} \sin \left(2 \beta_{1} h\right)}{2\left[\operatorname{sh}^{2}\left(\alpha_{1} h\right)+\cos ^{2}\left(\beta_{1} h\right)\right]}\right\} \times \\
& \times\left[1+\frac{A}{2 A_{1}}(\cos \omega t+\gamma \sin \omega t)\right] d t+ \\
& +\int_{t_{1}}^{t_{2}} \frac{E S}{\left(t_{1}+t_{2}\right)\left(1+\gamma^{2}\right) \omega^{2}}\left\{\frac{\alpha_{1} \operatorname{sh}\left(2 \alpha_{1} h\right)-\beta_{1} \sin \left(2 \beta_{1} h\right)}{2\left[s h^{2}\left(\alpha_{1} h\right)+\cos ^{2}\left(\beta_{1} h\right)\right]}\right\} \times \\
& \times\left[1+\frac{A}{2 A_{1}}(\cos \omega t+\gamma \sin \omega t)\right] d t .
\end{aligned}
$$

From this we find

$$
\begin{gathered}
m_{c}^{\prime}=\frac{E S \tau_{1}}{\left(1+\gamma^{2}\right) \omega^{2}\left(t_{1}+t_{2}\right)}\left\{\frac{\alpha_{1} \operatorname{sh}\left(2 \alpha_{1} h\right)-\beta_{1} \sin \left(2 \beta_{1} h\right)}{2\left[\operatorname{sh}^{2}\left(\alpha_{1} h\right)+\cos ^{2}\left(\beta_{1} h\right)\right]}\right\} ; \\
m_{c}^{\prime \prime}=\frac{E S \tau_{2}}{\left(1+\gamma^{2}\right) \omega^{2}\left(t_{1}+t_{2}\right)}\left\{\frac{\alpha_{1} \operatorname{sh}\left(2 \alpha_{1} h\right)-\beta_{1} \sin \left(2 \beta_{1} h\right)}{2\left[\operatorname{sh}^{2}\left(\alpha_{1} h\right)+\cos ^{2}\left(\beta_{1} h\right)\right]}\right\},
\end{gathered}
$$

where

$$
\tau_{1}=t_{1}+\frac{A}{2 \omega_{A_{1}}}\left[\sin \omega t_{1}+\gamma\left(1-\cos \omega t_{1}\right)\right]
$$

$\tau_{2}=t_{2}-t_{1}+\frac{A}{2 \omega A_{1}}\left[\sin \omega t_{2}-\sin \omega t_{1}+\gamma\left(\cos \omega t_{2}-\cos \omega t_{1}\right)\right]$.

To determine the active resistance, we use the following:

$$
b \frac{d z(t)}{d t}=i E S \gamma \frac{\partial u(0, t)}{\partial z}
$$

where $b$ - coefficient of inelastic resistance of cement-concrete mixture.

From the expression (41) follows:

$$
b=\frac{i E S \gamma \frac{\partial u(0, t)}{\partial z}}{\frac{d z(t)}{d t}} .
$$

Substituting expression (32) and oscillations acceleration of the movable frame $\frac{d z(t)}{d t}=\sum_{n=1}^{n} i n \omega A_{n} e^{i n \omega t}$ into formula (43), we obtain a functional dependence for determining the coefficient of inelastic resistance of a concrete mixture:

$$
b=\frac{\sum_{n=1}^{n} i E S \gamma A_{n}\left\{\frac{\alpha_{n} s h\left(2 \alpha_{n} h\right)-\beta_{n} \sin \left(2 \beta_{n} h\right)}{2\left[\operatorname{sh}^{2}\left(\alpha_{n} h\right)+\cos ^{2}\left(\beta_{n} h\right)\right]}\right\} e^{i n \omega t}}{\sum_{n=1}^{n} n \omega A_{n} e^{i n \omega t}}+
$$

$$
+\frac{\frac{i E S \gamma A}{2}\left\{\frac{\alpha_{1} \operatorname{sh}\left(2 \alpha_{1} h\right)-\beta_{1} \sin \left(2 \beta_{1} h\right)}{2\left[\operatorname{sh}^{2}\left(\alpha_{1} h\right)+\cos ^{2}\left(\beta_{1} h\right)\right]}\right\}}{\sum_{n=1}^{n} n \omega_{A_{n}} e^{i n \omega t}} .
$$

We determine in the first approximation the coefficient of inelastic resistance of a concrete mixture based on the values of the main frequency by forcing oscillations. At the same time expression (44) turns to the following form:

$$
\begin{aligned}
& b=\frac{i E S \gamma}{\omega}\left\{\frac{\alpha_{n} S h\left(2 \alpha_{n} h\right)-\beta_{n} \sin \left(2 \beta_{n} h\right)}{2\left[\operatorname{sh}^{2}\left(\alpha_{n} h\right)+\cos ^{2}\left(\beta_{n} h\right)\right]}\right\}+ \\
& +\frac{i E S \gamma A}{2 A_{1} \omega}\left\{\frac{\alpha_{1} \operatorname{sh}\left(2 \alpha_{1} h\right)-\beta_{1} \sin \left(2 \beta_{1} h\right)}{2\left[\operatorname{sh}^{2}\left(\alpha_{1} h\right)+\cos ^{2}\left(\beta_{1} h\right)\right]}\right\} e^{-i \omega t} .
\end{aligned}
$$

Separating from the complex function (45) the imaginary part, we find the desired value of the equivalent coefficient of inelastic resistance of the concrete mixture with asymmetric kinematic excitation of oscillations:

$b_{\text {экв }}=\frac{E S \gamma}{\omega}\left\{\frac{\alpha_{n} s h\left(2 \alpha_{n} h\right)-\beta_{n} \sin \left(2 \beta_{n} h\right)}{2\left[\operatorname{sh}^{2}\left(\alpha_{n} h\right)+\cos ^{2}\left(\beta_{n} h\right)\right]}\right\} \cdot\left[1+\frac{A}{2 A_{1}} \cos \omega t\right]$.

In paper [13] the dependences for determining the reduced mass and the equivalent coefficient of inelastic resistance of a concrete mixture during the vibration seal are given:

$$
\begin{aligned}
& m_{c}^{\prime}=\frac{2 \rho S\left(\alpha_{1} \operatorname{sh} 2 \alpha_{1} h+\beta_{1} \sin 2 \beta_{1} h\right) \tau_{1}}{\left(a_{1}^{2}+\beta_{1}^{2}\right)\left(\operatorname{ch} 2 \alpha_{1} h+\cos 2 \beta_{1} h\right)\left(\tau_{1}+\tau_{2}\right)} \text { if } 0 \leq t \leq \tau_{1} ; \\
& m_{c}^{\prime \prime}=\frac{2 \rho S\left(\alpha_{1} \operatorname{sh} 2 \alpha_{1} h+\beta_{1} \sin 2 \beta_{1} h\right) \tau_{2}}{\left(a_{1}^{2}+\beta_{1}^{2}\right)\left(\operatorname{ch} 2 \alpha_{1} h+\cos 2 \beta_{1} h\right)\left(\tau_{1}+\tau_{2}\right)} \text { if } \tau_{1} \leq t \leq T ; \\
& b_{\text {экв }}=\frac{\frac{E S \gamma}{\omega} \sum_{n=1}^{\infty} n \sqrt{\mu_{n}^{2}+v_{n}^{2}} \cos \left[n \omega t-\frac{d n}{a n}\right] N_{11}}{\sum_{n=1}^{n} n^{2} \sqrt{\mu_{n}^{2}+v_{n}^{2}} \cos \left[n \omega t-\frac{d n}{a n}\right]},
\end{aligned}
$$

which can only be used for approximate calculations.

\section{Conclusions}

As a result of the theoretical studies, the law of motion of the compacted medium is established and the stresses in the compacted layer of the concrete mixture are found, which allows, based on the well-known method [12], to determine the efficiency of the compaction process and the required compacted duration during the kinematic excitation of non-harmonic vibration oscillations. The experimental test showed that deductions and proposed by us correspondences (40), (41) and (44) give a difference $m_{c}^{\prime}, m_{c}^{\prime \prime}$ and $b_{\text {экв }}$ with experimental data no more than $15 \%$. At the same time, the value of the reduced mass and the equivalent coefficient of inelastic resistance of the concrete mixture during the vibration compaction $m_{c}^{\prime}, \quad m_{c}^{\prime \prime}$ и $b_{\text {экв }}$, which are determined by known dependencies (47-49) [12], give a difference with the experimental data no less $35 \ldots 40 \%$.

Thus, the obtained correspondences (38-41) and (46) determine the reactive and active supports of the medium by the oscillation of the actuating element of the shock machine.

It becomes possible to use the coefficients $b_{\text {экв }}$ and $m_{c}$ in the equations of the joint motion of the operating device and the medium, which include the concentrated parameters of the operating device and the distribution of parameters of the treated medium. The practical value of obtained data is the following: 
- does not need to find the coefficients that characterize the harmonic conditions in explicit form, which can significantly simplify the course of solutions;

- gives an opportunity to estimate the motion of the continuum medium in the implementation of complex laws of motion of the system with the wave processes saving.

\section{References}

[1] I.I. Nazarenko, Vibratsiyni mashyny i protsesy budivel'noyi industriyi, KNUBA, Kyiv, 2007, 230s. ISBN 978-966-627-134-7.

[2] Korobko BO, "Investigation of energy consumption in the course of plastering machine's work", Eastern-European Journal of Enter prise Technologies, Vol. 4/8 (82), (2016), ss. 4-11. https://doi.org/:10.15587/1729-4061.2016.73336.

[3] I.I. Blekhman, Vibratsionnaya mekhanika, Fizmatlit, Moskva, 1994, $400 \mathrm{~s}$.

[4] P.P. Deryabin, V.F. Zavadskiy, A.F. Kosach, V. A. Popov, Tekhnologiya stroitel'nykh izdeliy iz yacheistykh betonov, SibADI, Omsk:, 2004, 108 s.

[5] YU.M. Bazhenov, Tekhnologiya betona, ASV, Moskva, 2003, $500 \mathrm{~s}$.

[6] Zhigiliy SM, "Primeneniye kriteriyev podobiya pri matematicheskom modelirovnii tekhnologicheskoy vibromashiny", Voprosy vibratsionnoy tekhnologii, Vol. 1, (2006), ss.163-166.

[7] Nazarenko II, Ruchyns'kyy MM, Terenchuk SA, "Doslidzhennya rezhymnykh ta enerhetychnykh kharakterystyk prohresyvnykh vibromashyn", Visnyk NTUU «KPI», Vol. 63, (2011), ss.214-218. https://doi.org/10.20535/2305-9001.2011.63.58587.

[8] Nazarenko II, Sviders'kyy AT, Dyedov OP, "Stvorennya vysokoefektyvnykh vibroushchil'nyuyuchykh mashyn novoho pokolinnya", Visnyk NTUU «KPI», Vol. 63, (2011), ss.219-223. https://doi.org/10.20535/2305-9001.2011.63.58753.

[9] AH Maslov, Zhanar Bat-saykhan, "Opredelenye ratsyonal'nykh parametrov vybroudarnoho rabocheho orhana dlya uplotnenyya betonnykh smesey", Visnyk Kremenchuts'koho natsional'noho universytetu imeni Mykhayla Ostrohrads'koho, Vol. 4 (93), Chast. 1, (2015), ss. 58-64.

[10] Orysenko OV, Nesterenko MM, "Konstruktsiya udarnovstryakhivayushchey ustanovki dlya formovaniya stenovykh blokov iz legkikh betonov na osnove analiza konstruktivnykh osobennostey uplotnyayushchikh mashin", Materialy Mezhdunarodnoy nauchno-prakticheskoy konferentsii 2010g. G. Volgograd, Vol.1, (2011), ss. 227-233.

[11] Orysenko OV, Nesterenko MM, "Rozroblennya konstruktsiyi udarno-strushuval'noyi ustanovky dlya formuvannya stinovykh blokiv iz lehkykh betoniv na osnovi analizu konstruktyvnykh osoblyvostey ushchil'nyuyuchykh mashyn", Zbirnyk naukovykh prats': haluzeve mashynobuduvannya, budivnytstvo, Vol. 3(25), (2009), ss. 150-155.

[12] Orysenko OV, Nesterenko MM, 'Udarno-strushuval'na ustanovka dlya formuvannya stinovykh arbolitovykh blokiv iz lehkykh betoniv iz zastosuvannyam mineral'nykh v"yazhuchykh", Zbirnyk naukovykh prats': haluzeve mashynobuduvannya, budivnytstvo, Vol. 23, (2009), ss. 63-68.

[13] I.I. Nazarenko, Prykladni zadachi teoriyi vibratsiynykh system, Vydavnychyy Dim «Slovo», Kyiv, 2010, 440s. 